\title{
Postural set as a factor in short-term motor memory ${ }^{1,2}$
}

RICHARD A. SCHMIDT, University of Maryland, College Park, Md. 20740, and GEORGE E. STELMACH, University of Califormia, Santa Barbara, Calif. 93106

The present study attempted to differentiate between a set $v s$ an interference explanation of the decrements in recall when activities are included in the retention interval. Using a lever-positioning task with three retention intervals $(12,22$, and $37 \mathrm{sec}$ ) and two types of activity during the retention interval, it was found that movement caused a significant overestimation of the target position using algebraic error, and that a movement by retention interval interaction was not significant. Since the decrements in recall were independent of the retention interval length, the results indicated that the effect of movement was to reduce S's postural set. No differences were found when using absolute errors.

Bilodeau (1966) has reported some earlier work which indicated that the short-term retention of simple leverpositioning tasks was decreased if simple activities filled the retention interval. He found that if Ss released the lever, stood, moved out of the room, and returned to the lever during a retention interval of $3 \mathrm{~min}$, more decrement occurred than if Ss remained engaged with the apparatus during the retention interval. Similar results were later found by Boswell \& Bilodeau (1964), who found that stepping away from the apparatus and retrieving a pencil caused decrements in recall as compared with remaining engaged. Bilodeau (1966) has indicated that the decrements in recall could be a result of either a loss of postural set from the disengaging activities or interference from the motor activities during the retention interval.

One possible method of differentiating between these two hypotheses is based upon the assumption that the loss of set is an all-or-none occurrence, and that once the set has been lost, further activities during the retention interval will not cause further losses of set. Thus, if set is the only factor responsible for the decrements in the Bilodeau work, the decrement in response should be independent of the retention interval. If, on the other hand, interference was responsible for the decrements, the decrement should be an increasing function of the retention interval length, since longer intervals provide more opportunity for interfering traces to enter short-term memory. The present study attempted to differentiate between these two hypotheses by having Ss either remain engaged or move about during each of the three retention intervals. If Movement is a factor in retention, but the Time by Movement interaction is not, then one would argue for set, since additional time in movement did not produce an additional decrement as would be predicted by the interference hypothesis. However, if both Movement and the Time by Movement interaction are significant factors, one would argue for interference. The hypotheses were tested using a simple lever-positioning task with a design which enabled the independent variation of the length of. and a kind of, activity in the retention interval.

\section{METHOD}

\section{Apparatus}

The apparatus consisted of a lever which was attached to one end of a horizontally-mounted 3/8-in. axle which ran through three machined bushings. The lever was 16 in. long and was constructed so that a 6 in. solid steel handle ( 1 in. diam) could be mounted parallel to the axle near the end of the lever. A small ( 6 in.) pointer was attached to the other end of the axle and a protractor was mounted adjacent to the pointer so that lever displacement could be accurately measured. The system was finely machined and was nearly frictionless and free of "play." The apparatus was secured to the top of a standard (36 in.) table so that the handle extended over one edge.

The Ss sat in a hard-backed chair which was located adjacent to the table, and was situated in such a position that the lever handle was directly in front of his right shoulder. The lever positioning response was made in the sagittal plane about a lateral horizontal axis. The starting position was defined by a permanent stop peg so that the lever was inclined toward $\mathbf{S}$ at $60 \mathrm{deg}$ from horizontal and removable stop pegs defined three target positions $(105,120$, and $135 \mathrm{deg})$. In the starting position, the handle was approximately 7 in. in front of S's right shoulder, and $S$ grasped the handle with the right hand with the palm facing away. Thus, the movements to the target positions involved pushing the lever in the direction $S$ was facing.

Procedure

The blindfolded $\mathrm{S}$ was seated in the chair with his hand on the lever in the starting position. On the command "move," $\mathrm{S}$ moved the lever forward until the pointer hit the stop peg, where he remained for $3 \mathrm{sec}$. On the command "return" S moved the lever back to the starting position. When $S$ returned to the starting position the retention interval (either 12,22, or $37 \mathrm{sec})$ began. At this point half of the Ss remained seated with their hand on the lever for the entire retention interval. The other half released the lever and stood up on the command "Stand," immediately turned 90 deg to the left, touched the floor with the right hand, returned to a standing position, turned $90 \mathrm{deg}$ to the right, and remained standing until the end of the retention interval. Four sec before the end of the retention interval S sat down on the command "Sit" and regrasped the lever on the command "Lever." At the end of the retention interval for both groups, E said "Estimate," and $S$ attempted to place the lever at the previously defined target position with the stop peg removed. When $S$ felt he had achieved the correct position, he said "There" and the position was recorded to the nearest $0.1 \mathrm{deg}$. The above events defined a trial, and each $S$ had three trials, each with a different target position and retention interval, but with the same activity during the retention interval. The intertrial interval was constant at $65 \mathrm{sec}$. All intervals were controlled by an eight-blank decade interval timer.

The activities during the retention intervals were intended to produce losses in postural set by having $S$ release the lever and move away from the apparatus, and were designed to approximate those retention interval activities used by Boswell \& Bilodeau (1964). In addition, the activities were potentially interfering, since feedback from the arm as a result of movements and from the same position during the waiting period after the movement could interfere with the short-term trace from the target position.

Design

The design used three target positions $(105,120$, and 135 $\mathrm{deg})$ and three retention intervals $(12,22$, and $37 \mathrm{sec})$ which were counterbalanced in a Graeco-Latin squares design so that each $\mathbf{S}$ had each position and each retention interval (but not all combinations of intervals and positions) in three trials. Thus, the within Ss variables were target positions, retention intervals. and trials. The nature of activity during the retention interval (remaining engaged or standing up) was a between Ss variable.

The statistical design used was Winer's (1962, pp. 574-576) Plan 13, which used two identical orthogonal $3 \times 3$ 
(iracco-Latin squares. with 24 Ss randomly assigned to each scluare. The columns of the square were the three trials and the rows were the three subgroups composed of eight randomly assigned Ss. Thus each target position and each retention interval were represented once in each of the three trials.

Subjects

The Ss were 48 male and female graduate and undergraduate students at the California State College. Los Angeles and the University of California. Berkeley. There were 11 women and 37 men. They were randomly assigned to one of six groups (three rows per square and two squares) so that all eight Ss in a given group had the same order of presentation of retention interval and target position.

\section{Absolute Error}

\section{RESULTS}

An analysis of absolute error indicated that Retention Intervals, Type of Activity. the Retention Interval by Type of Activity interaction and all other main effects and interactions failed significance. Since absolute error is insensitive to the direction of error, it was decided to do the analysis using algebraic error.

Algebraic Error

An analysis of algebraic errors indicated that the group which remained engaged during the retention interval had an average error of $-5.73 \mathrm{deg}$ (undershoot) while the movement group had an average error of +4.37 deg (overshoot). This difference was significant with $F(1.42)=6.30, p<.01$. The Retention Interval by Movement interaction failed significance with $F(2,84)=0.37$. These findings would indicate that the effect of the interpolated movement was to make the responses too long, and that the activity did not produce greater decrements with the longer retention intervals. As the interference theor would predict that movement during longer retention intervals would be more interfering than Juring short intervals, it appears that the effect of the activity during the retention interval was to disnupt S's postural set and that apparently these activities were not interfering.

\section{DISCUSSION}

The finding that the nature of recall was not a function of the length of the retention interval made it unlikely the interference theory has explanatory power for the present results. These negative findings for interference in short-term motor memory join those of Adams \& Dijkstra (1966) and Posner \& Konick (1966) who found that retroactive and proactive inhibition, respectively, were not significant variables in short-tern motor memory. It should be noted, however, that the interfering activities in the present study were minimal in an attempt to approximate those procedures used by Boswell \& Bilodeau (1964). It is possible that a greater amount of activity would have produced a decrement which was related to the length of the interval.
The present findings indicated that motor activities filling the retintion interval caused a change in the pattern of recall because they reduced S's postural set toward the task. One possible source of the loss of postural set is that $S$ may have been seated well back in the chair when the target position wa. presented but after the movement, in spite of efforts to control the way in which $S$ was repositioned, he may have been positioned slightly too far forward in the chair. If this were the case, $S$ would tend to overestimate the position which was the effect of interpolated movement in the present study.

A substantial disagreement of the present study with those of Adams \& Dijkstra (1966), and Posner \& Konick (1966) was that the retention interval failed to be a significant variable for either absolute or algebraic error. In the no movement conditions, which were most analogous to the procedures of Adams and Dijkstra, the absolute errors were 3.21, 2.97, and $3.11 \mathrm{deg}$ for retention intervals of 12,22. and $37 \mathrm{sec}$ indicating the clear absence of forgetting trends with time in the present data. The reasons for the lack of absolute error increases with time are not clear, but there is the possibility that the present task is more insensitive to short-term forgetting than those used by Adams \& Dijkstra (1966) and Posner \& Konick (1966).

The present study has indicated that the loss of postural se may be a significant factor in short-term motor retention, especially if retention intervals are filled with motor activity which is intended to be interfering. Thus, it would appear that adequate controls for the loss of set should be used in such situations to insure that the decrements due to interpolated (potentially interfering) movement are not merely losses in postural set.

\section{REFERENCES}

ADAMS. J. A. \& DIJKSTRA, S. Short-term memory for motor responses. Journal of Experimental Psychology, 1966, 71, 314-318.

BILODEAU. E. A. Retention. In E. A. Bilodeau (Ed.), Acquisition of skill. New York: Academic Press, 1966.

BOSWELL, J. J., \& BILODEAU, E. A. Short-term retention of a simple motor task as a function of interpolated activity. Perceptual \& Motor Skills. 1964, 18, 227.230.

POSNER, M. I., \& KONICK, A. F. Short-term retention of visual and kinesthetic information. Organizational Behavior \& Human Performance, 1966, 1, 71-86.

WINER, B. J. Statistical principles in experimental design. New York: McGraw-Hill, 1962.

\section{NOTES}

1. This study was supported in part by Research Grant No. 571 from the Academic Senate of the University of California, Santa Barbara.

2. Appreciation is extended to T. L. Doolittle, California State College, Los Angeles, and F. M. Henry, University of California, Berkeley, for their cooperation in providing facilities and Ss. 